\title{
RISK-ORIENTED APPROACH TO COMPETITION ASSESSMENT IN THE GLOBAL RENEWABLE ENERGY SOURCES MARKET
}

\author{
GALINA CHEBOTAREVA \\ Academic Department of Energy and Industrial Enterprises Management Systems, Ural Federal University, Russia
}

\begin{abstract}
The growing pace of renewable energy development favors a significant change in global energy market conditions. This is due to the crisis of traditional energy, the emergence of new energy sources and arrival of new market players. As a result, forecasting the state of the energy market and assessing the potential of individual regions in terms of the development of renewable energy sources (RES) is becoming quite a difficult task. The article presents a structural analysis of the global energy market in the aspect of studying the dynamics of new capacity and actual production of renewable energy by country and type of energy sources. As a result of the analysis, the author has grouped countries participating in the market on the basis of indicator values reached: front-runners, average performers and stragglers. The author presents an approach for assessing competition in the global renewable energy market - a "thermometer" of competition. Its features include assessment of aggregate specific risk that is unique for each energy market country-member. The final assessment of the "temperature" in the global energy market is based on taking into account the total aggregate risk in one of the three zones of the "thermometer" scale. The results of the study will be used for improving the presented approach, developing an integrated methodology for the ranking of regions in the energy market, and the practice-based assessment of competition in the global market of renewable energy, taking into account the potential of individual participants.
\end{abstract}

Keywords: energy, renewable energy sources, distributed generation, global energy market, competition, competition "thermometer", competitiveness, risks, risk management.

\section{INTRODUCTION}

One of the urgent tasks of today's energy sector is to study the level of competition in the renewable energy sources (RES) market and evaluate the contribution that each region makes to the market development. Numerous studies [1]-[6] make it possible to assess the dynamics of the energy market, the level of RES technology advancement, political support, the volume of investments, etc. However, methodological tools for comprehensive assessment of all the factors that will enable one to judge the general state of the global RES market require further elaboration. Consequently, there is a complex task to perform not only a theoretical, but also an applied study of competition in the RES market taking into account specific characteristics that are presented in the article in the form of risks.

For the purpose of quantitative assessment, the author defines competition in the global energy market is the combined level of competitiveness of each market participant. The subjects of the study are regions producing renewable energy.

The outcome of the study is development of an original approach dubbed as "thermometer" for assessing competition in the global RES market. It makes it possible to study the level of competitiveness of each region in the market taking into account inherent risks. The article presents the features of all zones of the "thermometer", a classification of regions by rate of maximum capacity and actual production of renewable energy; specific risks in the RES market are determined. The obtained results have practical importance and will be used to improve the presented concept in terms of increasing the objectivity of evaluation and narrowing the subject to the countries and companies operating in the RES market. 


\section{GLOBAL RENEWABLE ENERGY MARKET}

The study of the global renewable energy market is based on the assessment of maximum capacity and actual production in the energy market, including the regional aspect. Market research was conducted using statistical data published by the International Renewable Energy Agency [1], [2], Renewable Energy Policy Network for the 21st. Century [3], [4] and other sources [7], [8].

\subsection{Maximum capacity of world renewable energy}

Since 2007, there has been a constant increase in the maximum capacity of the RES market. Asian countries have always been leaders in this market. Despite a fall in volumes in 2014, a year later, the Asian region more than doubled its growth, and in 2016 was able to regain the status of world leader. This result was achieved thanks to the markets of China, India and Japan. According to REN21 Century [3], Asian countries are in the top five in most ratings in terms of total RES capacity. Thus, China is the absolute leader in terms installed capacity of hydropower, solar PV power, wind power, etc. Indonesia, Japan, India and Vietnam are actively putting into operation geothermal power and solar CSP power installations (Table 1). The closest regions to Asia in terms of renewable energy capacity are the EU and North American countries (Fig. 1).

Depending on the relative growth in RES capacity all regions were divided into three groups (Fig. 1):

1. Regions that outpace the average global growth rate of RES - market leaders: Asia.

2. Regions where RES growth matches global average rates: Central America and the Caribbean, Europe, Africa and North America.

3. Other regions where the growth rate of renewable energy capacity is significantly behind the average level: Oceania, The Middle East, South America and Eurasia.

\subsection{Actual renewable energy production in the world}

In contrast to the capacity market, the actual generation of renewable energy is characterized by unstable dynamics. The commissioning of capacity was unstable only in 2014 in Asian countries, whereas today alternating growth and reduction in production is already characteristic of a number of countries (Fig. 2). In 2008, the reduction was observed in the countries of Oceania and Eurasia ( 3 and $7 \%$ ), while in the Middle East the indicator values more than halved; in 2011 1.5\% reduction in Eurasia and Europe (primarily the EU countries); in 2012 1.5\% in North, South America and Oceania. The 1\% average decrease in renewable energy production in South America has been observed annually. In Eurasia and the Middle East, the fall of the market in 2014 was the maximum: 9\% and 12\% respectively.

Table 1: Countries - world leaders in new RES capacity.

\begin{tabular}{|l|c|c|c|c|c|}
\hline RES types & 1 & 2 & 3 & 4 & 5 \\
\hline Geothermal power industry & USA & Philippines & Indonesia & Mexico & New Zealand \\
\hline Hydropower engineering & China & Brazil & USA & Canada & Russia \\
\hline Solar PV energy & China & Germany & Japan & USA & Italy \\
\hline Solar CSP energy & Spain & USA & India & Morocco & RSA \\
\hline Wind energy & China & USA & Germany & India & Spain \\
\hline Geothermal heat supply & China & Turkey & Japan & Iceland & India \\
\hline
\end{tabular}



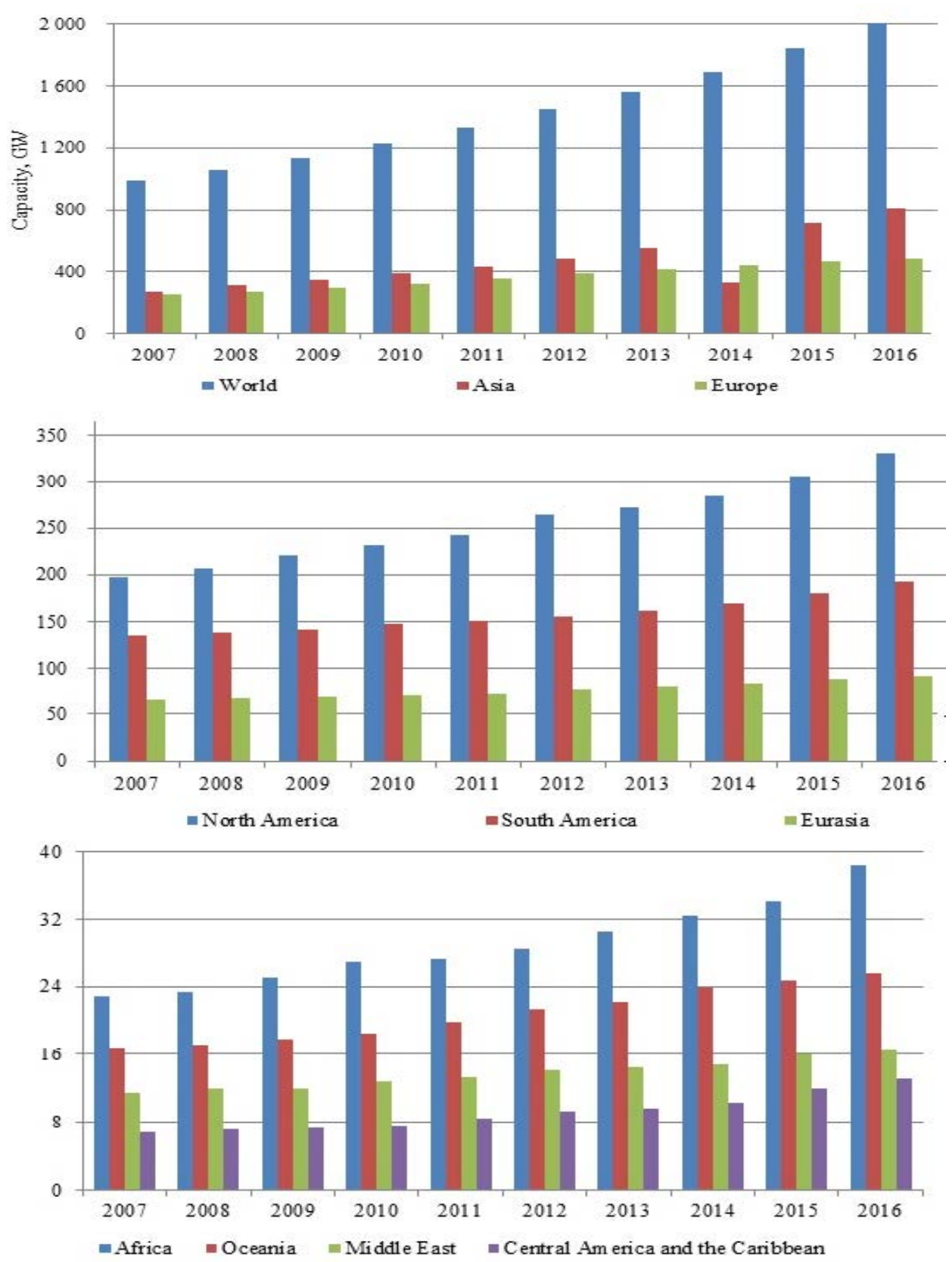

Figure 1: Dynamics of new RES capacity deployment in the world (2007-2016), GW. 

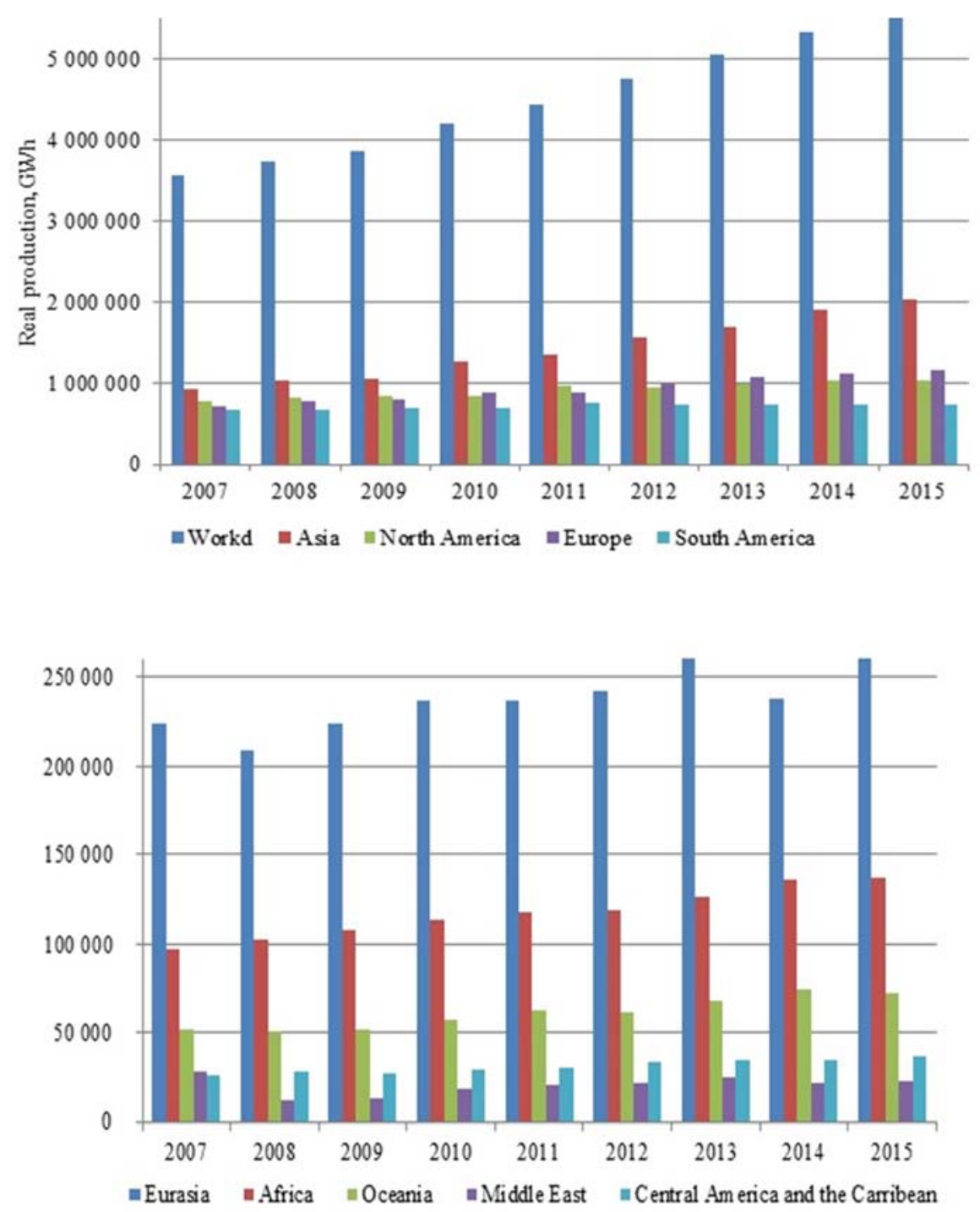

Figure 2: Dynamics of RES production in the world (2007-2015гг), GWh.

In general, between 2007 and 2015, occasional reduction in renewable energy production was typical primarily of average performing market participants. In most cases, it did not have a significant impact on global indicators and was offset by RES generation in the Asian region, as well as North America and Europe. Comparison of capacity deployment rates and production of RES energy showed that the energy generation market is lagging behind. The analysis enabled the author to classify the regions by volume of renewable energy production (Fig. 2): 
4. The largest renewable energy producing regions: the indicator is above 650,000 GWh: Asia, North America, Europe and South America (over $90 \%$ of the market).

5. Regions - average performing participants of the market with the volume of production within the 50,000-300,000 GWh range: Eurasia, Africa and Oceania $(8.6 \%)$.

6. Regions with the lowest energy production Central America and the Caribbean and the Middle East with annual output less than 50,000 GWh (about 1\% of the market).

\section{CONCEPT OF COMPETITION “THERMOMETER” IN THE GLOBAL ENERGY MARKET}

The essence of the "thermometer" concept is to assess the level of competition in the global RES market by evaluating the competitiveness of each market participant.

\subsubsection{Methodical basis of competition "thermometer"}

The quantitative indicator of competitiveness is the level of aggregate risk $(R)$ that is inherent in each participant and includes multiple individual risks $\left(r_{j}\right)$; the quantitative indicator of competition is the total aggregate risk $\left(R_{\Sigma}\right)$ as the sum total of aggregate risks for all market participants. Competitiveness and aggregate risk, as well as competition and total aggregate risk are inversely proportional to each other.

The fundamental principle of the "thermometer" is: the higher the level of total aggregate risk, the weaker is competition in the energy market. In practice, the concept involves assessing the deviation of the actual value of $R_{\Sigma}$ in the energy market from the normative values (Fig. 3): where $\mathrm{n}$ is the value of $R_{\Sigma}$ within which the energy market has the greatest competition; $n_{1}$ and $n_{2}$ are the borderlines of the subzone within the third zone.

Assessment of competition using the "thermometer" consists of nine main stages:

1. Identification of individual risks that characterize the standing of the global RES market participants;

2. Assessment of indicators of individual risks (maximum and minimum probability, level of risk influence);

3. Assessment of the total risk of each participant in the global RES market $\left(R_{1}, R_{2}, \ldots\right.$, $R_{m}$ ) based on the theory of total risk [9], [10];

4. Calculation of the actual value of the total aggregate risk in the market $\left(R_{\Sigma}\right)$ by the eqn (1) and assessment of the current zone (subzone) of the energy market:

$$
R_{\Sigma}=\sum_{i=1}^{m} R_{i}
$$

5. Expert assessment of the borderline of the zones and sub-zones of "thermometer" $\left(n, n_{1}\right.$ and $n_{2}$ ). It depends on the number of market participants;

6. Calculation of $\Delta n_{\text {real }}$ - the difference between the total aggregate risk and the lower borderline of the relevant zone $\left(n_{i}\right)$ by eqn (2):

$$
\Delta n_{\text {real }}=R_{\Sigma}-n_{i}
$$

7. Calculation of $\Delta n_{\text {real }}^{\prime}$ - the difference between the total aggregate risk and the upper borderline of the relevant zone $\left(n_{i}^{\prime}\right)$ by the eqn (3):

$$
\Delta n_{\text {real }}^{\prime}=R_{\Sigma}-n_{i}^{\prime}
$$


8. Interpretation of the $\Delta n_{\text {real }}$ and $\Delta n_{\text {real }}^{\prime}: \Delta n_{\text {real }}$ shows what amount of risk that needs to be overcome to enter the area with a high level of competition; $\Delta n_{\text {real }}^{\prime}$ characterizes the stock of resilience which energy market has to avoid entering the area with a low level of competition.

9. Assessment of the prospects for the energy market development that is based on the indicators $\Delta n_{\text {real }}$ and $\Delta n_{\text {real }}^{\prime}$ : development of measures to increase competition in the RES marker, risk management programs, etc.

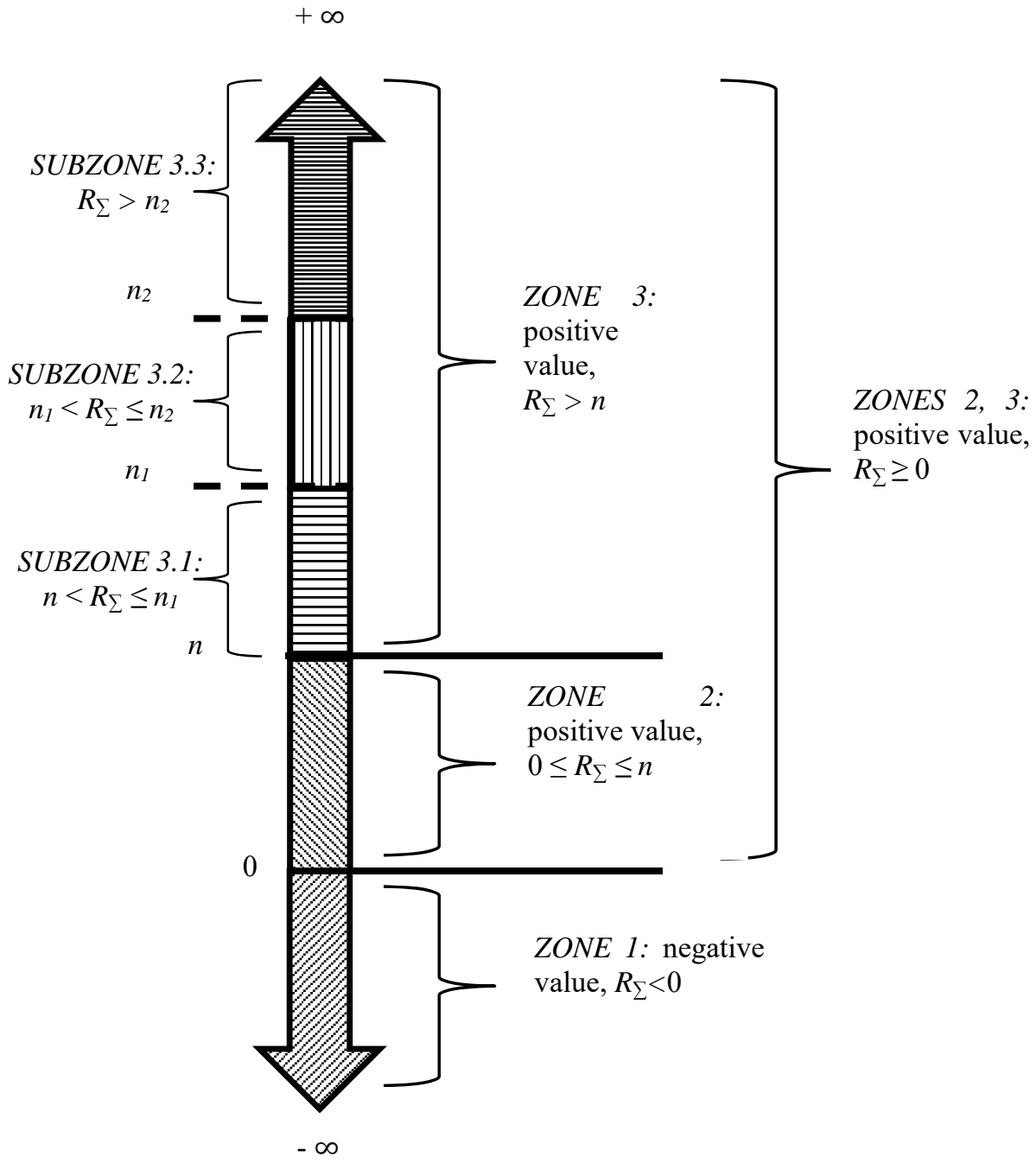

Figure 3: Graphical interpretation of competition "thermometer". 


\subsection{Brief characteristic of competition "thermometer" zones}

The competition "thermometer" includes three main zones and three subzones (Fig.3).

In zone 1 , the total aggregate risk takes only a negative value $\left(R_{\Sigma} \in(0 ;-\infty)\right)$. This means that all participants in the energy market are characterized by the absence of "active" risks: its impact, probability of default, the volume of losses tend to be zero, and unlikely riskinduced losses are fully covered by accumulated reserves. In practice, this situation is impossible as a sufficient number of exsogenous risks cannot be neutralized and all market participants cannot equally possess a highly effective risk management system and sufficient capital for its purposes.

When getting into zone $2\left(R_{\Sigma} \in[0 ; n]\right)$, the energy market has the highest level of competition: almost all the participants hold a strong competitive position as regards the implementation of RES projects. As a result, the struggle for limited investments, government support, consumers, etc. in the energy market becomes fiercer.

If $R_{\Sigma}$ enters zone $3(n ;+\infty)$, the competitiveness of market participants decreases, and the level of competition on the energy market weakens. It means that a number of market participants face a high level of risk. When the energy market enters the third zone, it is necessary to estimate the number of participants who drive this shift. In the third zone there are three subzones.

Subzone $3.1\left(R_{\Sigma} \in\left(n ; n_{1}\right]\right)$ is characterized by the possibility of the energy market rapdily moving back into the second zone. Getting into this subzone may be caused by a high level of risk for one or two participants in the energy market.

In subzone $3.2\left(R_{\Sigma} \in\left(n_{1} ; n_{2}\right]\right)$, the energy market perpetuates its status as that with declining competition. In such a situation, about five participants are not competitive. To exit this subzone, an increase in the amount of funds invested in risk management programs is required.

If the the energy market enters subzone $3.3\left(R_{\Sigma} \in\left(n_{2} ;+\infty\right)\right)$, this indicates a critically high level of total aggregate risk and the need for significant investment. Escaping this subzone is difficult.

\subsection{Auxiliary tools for "thermometer" assessment}

As auxiliary methodical tools for competition "thermometer" assessment, the theory of the aggregate risk is used [9], [10]. According to it, the aggregate risk includes a variety of individual risks and is calculated as the average value of the maximum and minimum risk level by the eqn (4). This indicator is a dimensionless value and is used for comparative evaluation and calculation of the monetary equivalent.

$$
R=\frac{R^{\max }+R^{\min }}{2}
$$

where $\mathrm{R}$ is the risk level; $R^{\max }=\frac{1}{2} *\left(\sum_{j=1}^{k}\left(p_{j}^{\max } * p_{j+1}^{\max } * \sin \gamma_{j+1}\right)+p_{1}^{\max } * p_{k}^{\max } *\right.$ $\left.\sin \gamma_{k}\right)$ is maximum risk level; $R^{\text {min }}=\frac{1}{2} *\left(\sum_{j=1}^{k}\left(p_{j}^{\text {min }} * p_{j+1}^{\text {min }} * \sin \gamma_{j+1}\right)+p_{1}^{\text {min }} * p_{k}^{\text {min }} *\right.$ $\left.\sin \gamma_{k}\right)$ is minimum risk level; $p_{j}^{\max }$ is maximum $\mathrm{j}$-th risk probability; $p_{j+1}^{\max }$ is maximum $(\mathrm{j}+1)$-th risk probability; $\gamma_{j+1}$ is $(\mathrm{j}+1)$-th risk level of influence on competitiveness (from 0 to 90 degree); $p_{j}^{\text {min }}$ is minimum $\mathrm{j}$-th risk probability; $p_{j+1}^{\min }$ is minimum $(\mathrm{j}+1)$-th risk probability. 
4 PRACTICAL APPLICATION OF THE COMPETITION “THERMOMETER” IN THE GLOBAL MARKET OF RENEWABLE ENERGY SOURCES

\subsection{Specific risks in RES market}

Among the private specific risks arising in the RES market the following are highlighted [3][5], [11]:

- Incorrect placement of RES installations $\left(r_{1}\right)$ - inefficient regional distribution of renewable energy facilities.

- Instability of the mechanisms of government support of RES projects leads to the emergence of legislative risks $\left(r_{2}\right)$ [12].

- Dependence of investors on government support $\left(r_{3}\right)$ at all stages of a project. Usually this is due to the volume and duration of the support being provided.

- Frequent changes in support schemes contribute to the low efficiency of the mechanisms of government and regional incentives $\left(r_{4}\right)$ for RES development in some areas [13].

- The high cost $\left(r_{5}\right)$ of renewable energy: higher adjusted cost of renewable energy (LCOE) compared to traditional energy sources [14], [15].

- Low effectiveness of adoption of RES technologies $\left(r_{6}\right)$ : in comparison with the cost of replacement or repair of worn-out basic production assets of energy companies / adoption of new conventional energy technologies [15]-[17].

- Reduction in private investment $\left(r_{7}\right)$ in renewable energy projects due to lower effective and investment attractiveness [18].

- Environmental risks $\left(r_{8}\right)$ : an increase in energy companies' expenditures on environmental safety measures compared to conventional energy sources [19]-[21].

- Slow pace of RES market development $\left(r_{9}\right)$ : share of renewable energy in the energy balance, share of electricity generated by RES, "natural" demand on renewable energy.

- High pace of conventional energy market development $\left(r_{10}\right)$ : the volume of current and prospective hydrocarbon reserves. It has a direct influence on demand, the cost of electricity and efficiency of RES projects.

- Fossil fuel subsidy $\left(r_{11}\right)$, which distorts the real cost of energy [3]-[5].

- Slow pace of distributed power generation development $\left(r_{12}\right)$ in the RES sphere.

- Shortage of qualified personnel $\left(r_{13}\right)$ in various areas of RES [3].

- Low consumer confidence and lack of awareness $\left(r_{14}\right)$ of renewable energy alternatives [3].

\subsection{Competition assessment in the global RES market}

To assess competition in the RES market three regions were selected by experts: Asia, North America and Europe - based on the results of the analysis of the global market (paragraph 2 ). The selection criteria were high performance indicators of maximum capacity and real production of renewable energy. These regions are among the leaders and therefore have the highest level of competitiveness in the market.

Table 2 shows the distribution of individual (rj), aggregate $(\mathrm{R})$ and total aggregate $\left(\mathrm{R} \sum\right.$ ) risks values by region and market. The expert evaluation is based on data from sources [1][4].

According to the methodology [9] for each study region, individual risks are ranked according to the following criteria in the sequence: impact level, maximum and minimum probabilities. The resulting rating is the basis for calculating the aggregate risk. 
Table 2: Risks' distribution across RES market regions.

\begin{tabular}{|c|c|c|c|c|c|c|c|c|c|}
\hline \multirow{2}{*}{$\begin{array}{l}\text { Regions } \\
\text { Risks' } \\
\text { symbols } \\
\end{array}$} & \multicolumn{3}{|c|}{ Asia } & \multicolumn{3}{|c|}{ North America } & \multicolumn{3}{|c|}{ Europe } \\
\hline & $\begin{array}{c}p^{\max }, \\
\%\end{array}$ & $\begin{array}{c}p^{\min } \\
\%\end{array}$ & $\begin{array}{c}\gamma, \\
\text { degree } \\
\end{array}$ & $\begin{array}{c}p^{\max } \\
\%\end{array}$ & $\begin{array}{c}p^{\min } \\
\%\end{array}$ & $\begin{array}{c}\gamma, \\
\text { degree } \\
\end{array}$ & $\begin{array}{c}p^{\max }, \\
\%\end{array}$ & $\begin{array}{c}p^{\min } \\
\%\end{array}$ & $\begin{array}{c}\gamma, \\
\text { degree } \\
\end{array}$ \\
\hline$r_{1}$ & 15 & 5 & 30 & 24 & 8 & 35 & 30 & 10 & 45 \\
\hline$r_{2}$ & 4 & 1 & 5 & 5 & 3 & 20 & 7 & 3 & 50 \\
\hline$r_{3}$ & 15 & 5 & 30 & 7 & 3 & 15 & 10 & 2 & 45 \\
\hline$r_{4}$ & 5 & 1 & 10 & 15 & 8 & 25 & 8 & 5 & 35 \\
\hline$r_{5}$ & 15 & 9 & 15 & 17 & 10 & 30 & 20 & 8 & 20 \\
\hline$r_{6}$ & 23 & 10 & 25 & 20 & 10 & 28 & 25 & 15 & 25 \\
\hline$r_{7}$ & 10 & 5 & 20 & 12 & 5 & 25 & 10 & 5 & 50 \\
\hline$r_{8}$ & 15 & 3 & 15 & 15 & 3 & 15 & 15 & 3 & 15 \\
\hline$r_{9}$ & 10 & 3 & 15 & 15 & 5 & 20 & 12 & 5 & 20 \\
\hline$r_{10}$ & 35 & 20 & 45 & 35 & 20 & 55 & 30 & 15 & 40 \\
\hline$r_{11}$ & 20 & 10 & 20 & 35 & 25 & 40 & 20 & 7 & 40 \\
\hline$r_{12}$ & 15 & 9 & 20 & 8 & 3 & 10 & 15 & 3 & 30 \\
\hline$r_{13}$ & 30 & 18 & 40 & 40 & 20 & 50 & 40 & 20 & 50 \\
\hline$r_{14}$ & 10 & 7 & 20 & 15 & 7 & 15 & 25 & 12 & 25 \\
\hline$R$ & \multicolumn{3}{|c|}{$\mathbf{0 . 0 5 9 0}$} & \multicolumn{3}{|c|}{0.1175} & \multicolumn{3}{|c|}{0.0716} \\
\hline$R_{\Sigma}$ & \multicolumn{9}{|c|}{0.2481} \\
\hline
\end{tabular}

Table 3: Expert assessment of zone (subzone) borderlines of competition "thermometer".

\begin{tabular}{|c|c|}
\hline Symbol of zone (subzone) & Qualitative assessment \\
\hline$n_{2}$ & 1 \\
\hline$n_{1}$ & 0.7 \\
\hline $\boldsymbol{n}$ & $\mathbf{0 . 3}$ \\
\hline 0 & 0 \\
\hline
\end{tabular}

The obtained result of the total aggregate risk is compared with the borderlines of the "thermometer". The calculation of zone (subzone) borderlines is based on expert assessment, the results of which are presented in Table 3. The experts were the heads of services and departments of Russian energy companies, as well as employees of Ural Federal University who are experts in the field of renewable energy and energy saving.

The obtained results place the global RES market represented by three regions in the second zone of the "thermometer": $R_{\Sigma} \in[0 ; 0.3]$. It is a zone of a high level of competition in the energy market, in which almost all regions have reached an optimal level of aggregate risk. It means that the probability of default of RES projects is reduced; resources for new projects are released. These results confirm the conclusions drawn from the analysis of the global RES market. Asia, North America and Europe are the market leaders and boast a high level of competitiveness.

However, in accordance with the experts assessment, each of the regions should account for no more than 0.3 of risk, i.e., on average 0.1 per region. This condition is fulfilled only by Asia and Europe: their indicators do not exceed the established limit, and also have a risk reserve of 0.041 and 0.0284 respectively. The North American region exceeds the required risk level by 0.0175 . However, the market in overall continues to have a risk reserve of 0.0519 . 


\section{CONCLUSION}

In the process of forecasting the development of the global energy market in terms of RES it is particuarly important to design an approach that makes it possible to quantify the level of competition in the market while taking into account the standing of all regions involved. The author proposes a solution to this problem in the form of the concept of a competition "thermometer". What makes it special is that it enables a study of the set of specific risks, the allocation of zones and subzones of the competition "thermometer". As a result of the integration of all indicators into the model, it became possible to assess the competitiveness (aggregate risk) of regions and competition (total aggregate risk) in the market.

The concept can get further methodlogical development in the following directions:

- Expert assessment of the borderlines of zones (subzones) of the "thermometer" (n, $\mathrm{n} 1$ and $\mathrm{n} 2$ ): creation of an international pool of experts in the fields of renewable energy and energy efficiency, elaboration of questionnaires, justification of the scale of the thermometer, etc.

- Development of approaches to calculating the boundaries of the "thermometer" based on deterministic methods of evaluation. This will improve the validity of the results and the objectivity of the assessment of competition in the energy market. To do that, it is necessary to study the dependence of the total risk of each region on a set of macroeconomic indicators of the state of the energy market and the region, etc., evaluation of the significance of each indicator.

- Development of methodological tools to assess the monetary equivalent of aggregate and total aggregate risks. The purpose of such a mechanism should be to study the overall capital needs of the energy market for competition management.

The application prospects of the "thermometer" are mainly related to the narrowing of the research subject to the countries participating in the market and specific energy companies. This will make it possible to assess the overall risk of the energy market on the basis of data from individual companies and will increase the objectivity of the results.

\section{ACKNOWLEDGMENT}

The work was supported with a grant of the Russian Science Foundation (project № 17-7810039).

\section{REFERENCES}

[1] International Renewable Energy Agency (IRENA). Renewable Energy Statistics 2017. http://www.irena.org/DocumentDownloads/Publications/IRENA_Renewable_Energy Statistics_2017.pdf. Accessed on: 10 Jan. 2018.

[2] International Renewable Energy Agency (IRENA), Renewable energy highlights. http://www.irena.org/DocumentDownloads/Publications/IRENA_Renewable_energy highlights_July_2017.pdf. Accessed on: 10 Feb. 2018.

[3] Renewable Energy Policy Network for the 21 st Century (REN21), State of renewable energy, 2016, Global report. http://www.ren21.net/wp-content/uploads/2016/ 10/REN21_GSR2016_KeyFindings_RUSSIAN.pdf. Accessed on: 11 Feb. 2018.

[4] Renewable Energy Policy Network for the 21st Century (REN21), State of renewable energy, 2017, Global report. http://www.ren21.net/wp-content/uploads/2017/10/178399_GSR_2017_KEY-FINDINGS_RU_low.pdf. Accessed on: 20 Mar. 2018. 
[5] Ermolenko, G.V., Tolmacheva, I.S., Ryapin, I.Y., Fetisova, Y.A., Matshura, A.A. \& Reutiva, A.B., Handbook on Renewable Energy the European Union, Institute of Energy SRU GSE: Moscow, p. 96, 2016.

[6] Nabielek, P., Dumke, H. \& Weninger, K., Balanced renewable energy scenarios: a method for making spatial decisions despite insufficient data, illustrated by a case study of the Vorderland-Feldkirch Region, Vorarlberg, Austria. Energy, Sustainability and Society, 8(1), p. 5, 2018.

[7] Porfirev, B.N., Green trends in the global financial system. World Economy and International Relations, 60(9), pp. 5-16, 2016.

[8] KPMG, Prospects of development of electric power industry in Europe from the point of view of credit institutions. https://assets.kpmg.com/content/dam/kpmg/ pdf/2014/07/S_PU_1r.pdf. Accessed on: 10 Jan. 2018.

[9] Domnikov, A., Chebotareva, G. \& Khodorovsky, M., Unbiased investment risk assessment for energy generating companies: rating approach. International Journal of Sustainable Development and Planning, 12(7), pp. 1168-1177, 2017.

[10] Domnikov, A., Chebotareva, G. \& Khodorovsky, M., Evaluation of investor attractiveness of power-generating companies: special reference to the development risks of the electric power industry. WIT Transactions on Ecology and the Environment, vol. 190, pp. 199-210, 2014.

[11] Chebotareva, G., Researching the risks of Russian energy companies in the context of renewable energy sources development. WIT Transactions on Ecology and the Environment, vol. 224, pp. 45-56, 2017.

[12] International Finance Corporation (IFC), Russian politics in the sphere of renewable energy sources. http://www.ifc.org/wps/wcm/connect/6834db8040c81109b86ebd 5d948a4a50/Green\%20Giant\%20RUS.pdf?MOD=AJPERES. Accessed on: 22 Mar. 2018.

[13] Daniilidis, A. \& Herber, R., Impact of technical and economic uncertainties on the economic performance of a deep geothermal heat system. Renewable Energy, 114(B), pp. 805-816, 2017.

[14] Ghoddusi, H., Price risks for biofuel producers in a deregulated market. Renewable Energy, 114(B), pp. 394-407, 2017.

[15] John, S.G. \& Lakshmanan T., Cost optimization of dish solar concentrators for improved scalability decisions. Renewable Energy, 114(B), pp. 600-613, 2017.

[16] Budischak, C. et al., Cost-minimized combinations of wind power, solar power and electrochemical storage, powering the grid up to $99.9 \%$ of the time. J. Power Sources, 225, pp. 60-74, 2013.

[17] Windpower Cost Imperative Drives Monopiles to New Depths. www.windpoweroffshore.com/article/1210058/depth-cost-imperative-drivesmonopiles-new-depths. Accessed on: 23 Mar. 2018.

[18] Deloitte Establishing the Investment Case: Wind Power. http://tinyurl.com/deloittewind-investment-2014. Accessed on: 01 Apr. 2018.

[19] Stanek, W., Czarnowska, L., Gazda, W. \& Simla, T., Thermo-ecological cost of electricity from renewable energy sources. Renewable Energy, Submitted for publication, 2017.

[20] Hdidouan, D. \& Staffell, I., The impact of climate change on the levelised cost of wind energy. Renewable Energy, 101, pp. 575-592, 2017.

[21] Pryor, S. et al., Analyses of possible changes in intense and extreme wind speeds over northern Europe under climate change scenarios. Dyn., pp. 189-208, 2012. 